\title{
Biomarkers in airway diseases
}

\author{
Janice $M$ Leung $M D^{1}$, Don D Sin MD MPH',
}

\begin{abstract}
JM Leung, DD Sin. Biomarkers in airway diseases. Can Respir J 2013;20(3):180-182.

The inherent limitations of spirometry and clinical history have prompted clinicians and scientists to search for surrogate markers of airway diseases. Although few biomarkers have been widely accepted into the clinical armamentarium, the authors explore three sources of biomarkers that have shown promise as indicators of disease severity and treatment response. In asthma, exhaled nitric oxide measurements can predict steroid responsiveness and sputum eosinophil counts have been used to titrate anti-inflammatory therapies. In chronic obstructive pulmonary disease, inflammatory plasma biomarkers, such as fibrinogen, club cell secretory protein-16 and surfactant protein D, can denote greater severity and predict the risk of exacerbations. While the multitude of disease phenotypes in respiratory medicine make biomarker development especially challenging, these three may soon play key roles in the diagnosis and management of airway diseases.
\end{abstract}

Key Words: Airway disease; Asthma; Biomarkers; Chronic obstructive pulmonary disease

$\mathrm{R}$ espirologists have long relied on symptoms and pulmonary function to diagnose and manage airway diseases; however, this approach is suboptimal. By their very nature, symptoms are subjective (and thus difficult to measure) and often nonspecific, resulting in diagnostic and prognostic misclassification. Spirometry is also limited in that measurements reflect disease severity rather than activity, and correlate only weakly with clinical outcomes such as exacerbations, health status or mortality (1). Moreover, access to spirometry is variable, in certain settings limited, and highly trained personnel are required for proper execution and interpretation of data. A surrogate marker - one that can be measured in standard fashion and accurately reflects disease activity - could enhance patient care by providing additional information to the clinician. Useful biomarkers should, therefore, fulfill key certain criteria: that they consistently relate to a disease; represent biologically plausible pathways; and change in accordance with disease state (2). Despite their theoretical appeal, however, few effective biomarkers exist in respirology. The diversity of disease manifestations, in addition to the inherently heterogeneous environment of the respiratory tract, make the development of sensitive and specific pulmonary biomarkers particularly challenging.

The most promising biomarkers currently available in respiratory medicine relate to airway diseases such as asthma and chronic obstructive pulmonary disease (COPD). Exhaled gases and sputum cell counts have become promising tools in the management of asthma, while plasma biomarkers have shown potential for predicting the risk of COPD exacerbations and grading disease severity. In the present review, we focus our attention on these three sources of biomarkers, demonstrating how they can be usefully implemented in asthma and COPD patients.

\section{FRACTION OF EXHALED NITRIC OXIDE AND ASTHMA}

In lung tissue, nitric oxide (NO) plays a ubiquitous and wide-ranging role, serving as an integral mediator in vasodilation, inflammation and

\section{Les biomarqueurs des maladies des voies respiratoires}

Les limites de la spirométrie et des antécédents cliniques ont incité les cliniciens et les scientifiques à rechercher d'autres marqueurs des maladies des voies respiratoires. Même si peu de biomarqueurs sont largement acceptés parmi la panoplie d'outils cliniques, les auteurs explorent trois sources de biomarqueurs qui se sont révélées prometteuses comme indicateurs de la gravité de la maladie et de la réponse thérapeutique. En cas d'asthme, les mesures de la fraction expirée du monoxyde d'azote peuvent prédire la réponse des stéroïdes, tandis que la numération des éosinophiles dans les expectorations est utilisée pour titrer les thérapies anti-inflammatoires. En cas de maladie pulmonaire obstructive chronique, les biomarqueurs du plasma inflammatoire, comme le fibrinogène, la protéine des cellules de Clara et la protéine du surfactant, peuvent être indicateurs d'une plus grande gravité et prédire un risque d'exacerbations. Bien que la multitude de phénotypes pathogènes en médecine respiratoire rende l'élaboration de biomarqueurs particulièrement complexe, ces trois sources de biomarqueurs pourraient bientôt jouer un rôle crucial dans le diagnostic et la prise en charge des maladies des voies respiratoires.

neurotransmission. Its production in airway epithelial cells from L-arginine is regulated by inducible $\mathrm{NO}$ synthase. In the presence of airway inflammation, the activation of inducible NO synthase increases NO levels that are then detectable in exhaled breath by chemiluminescence analyzers. This test, noninvasive and easily performed by patients (2), is believed to indirectly measure the degree of inflammation in the airways.

In 1993, Alving et al (3) became the first to demonstrate that fraction of exhaled NO (FeNO) levels could reliably distinguish mild atopic asthmatic patients (who had two- to threefold higher FeNO levels) from nonasthmatic patients. Since then, numerous trials have sought to determine a role for FeNO levels in the management of asthma. Currently, the strongest evidence supports the ability of high FeNO levels to predict eosinophilic airway inflammation and, by extension, patient responsiveness to corticosteroid therapy. In a prospective cohort study by Smith et al (4), asthmatic patients with FeNO levels $>47$ parts per billion (ppb) were found to experience the greatest improvements in spirometry, peak flows and respiratory symptoms following four weeks of inhaled fluticasone therapy. Compared with clinical benchmarks often used in asthma, such as forced expiratory volume in $1 \mathrm{~s}$ per cent predicted and peak flow variability, FeNO levels were more predictive of steroid responsiveness. The use of FeNO to predict steroid responsiveness has since been incorporated into standard guidelines (5). Adult patients with FeNO levels $<25 \mathrm{ppb}(<20 \mathrm{ppb}$ in children) are believed to be less responsive to steroids whereas levels $>50 \mathrm{ppb}$ ( $>35 \mathrm{ppb}$ in children) predict a higher likelihood of a clinical response to steroids.

The largest randomized controlled trials (RCTs) regarding FeNO have focused primarily on its use in determining steroid dosing, with mixed results. In 2005, Smith et al (6) randomly assigned 97 asthma patients to stepwise inhaled corticosteroid (ICS) dose increases based on either clinical parameters or FeNO levels $>15 \mathrm{ppb}$. Although a $45.6 \%$ reduction in exacerbation rate did not achieve statistical significance, individuals assigned to the FeNO group had a significantly

${ }^{1}$ Critical Care Medicine Department, National Institutes of Health, Bethesda, Maryland, USA; ${ }^{2}$ UBC James Hogg Research Centre, St Paul's

Hospital; ${ }^{3}$ Division of Respiratory Medicine, Department of Medicine, University of British Columbia, Vancouver, British Columbia

Correspondence: Dr Janice M Leung, Critical Care Medicine Department, National Institutes of Health, 10 Center Drive,

Room 2C145, Bethesda, Maryland 20892, USA. Telephone 301-326-7719, fax 301-402-1213, e-mail janice.leung@nih.gov 
lower mean daily ICS dose. These findings, however, conflicted with the largest study to date investigating FeNO-guided management, a 2008 RCT of 546 inner-city adolescents and young adults who were randomly assigned to either a FeNO- or guideline-based treatment algorithm (7). No differences in asthma symptoms or exacerbation rates were found; moreover, the FeNO group had a higher daily ICS dose. Differences in statistical power, study populations and cut-off levels of FeNO used for titration could have resulted in these conflicting conclusions. Nonetheless, a subsequent meta-analysis of six RCTs (8) could not detect any benefit of using FeNO levels for exacerbation or symptom reduction. Therefore, while FeNO levels may be able to predict steroid responsiveness, titration of steroids based on FeNO levels cannot be recommended at this time.

\section{SPUTUM EOSINOPHILS AND ASTHMA}

While technically more difficult to perform than FeNO measurements, sputum induction can shed light on the cellular processes involved in asthmatic airways. In particular, the prevailing understanding of asthma as an eosinophilic-predominant process has led many to consider sputum eosinophil count as a diagnostic method. Sputum eosinophil counts $>3 \%$ have traditionally been believed to represent eosinophilic inflammation, helping to distinguish asthma from the more neutrophilic inflammation that marks COPD. When such a cutoff is used, the sensitivity for detecting asthma can reach as high as $86 \%$ (9). Still, caution should be applied to these criteria because noneosinophilic asthma and eosinophilic-predominant COPD can occur.

Unlike FeNO, RCTs on sputum eosinophil counts have consistently shown value in guiding medication dosages. This was first demonstrated in 2002 when Green et al (10) randomly assigned 74 asthmatic patients to 12 months of steroid dosing based on either normalizing sputum eosinophil count or standard symptom guidelines. Although the daily dose of ICS or oral steroids did not differ between the two patient groups, the rate of severe asthma exacerbations and hospitalizations was significantly lower in those managed according to sputum eosinophil count. A larger trial consisting of 117 adults followed over two years confirmed these results: while ICS doses remained the same, the frequency of exacerbations was considerably lower in the group who had sputum eosinophil based-titrations of therapy (11). Based on a subsequent meta-analysis in which treatment strategies derived from sputum eosinophil counts consistently protected against asthma exacerbations (OR 0.49; number needed to treat $=6$ ) $(12)$, strong recommendations can be made to incorporate this biomarker into treatment algorithms.

\section{BLOOD BIOMARKERS AND COPD}

Biomarkers derived from blood are appealing given the uniformity of sample collection when compared with the more technically demanding FeNO and sputum induction. Although many proposed blood biomarkers remain relevant only for research purposes and have yet to be applied universally in the clinical setting, we review several promising ones that may soon play a role in the management of COPD patients. The most widely studied biomarkers in this population capitalize on the inflammatory nature of COPD, operating under the principle that lung inflammation spreads to the systemic circulation where it can be measured in the blood. Fibrinogen, a well-known inflammatory and procoagulant biomarker often used in cardiovascular and autoimmune diseases, has been extensively studied in COPD patients, with elevated levels tracking well with baseline lung function, acute exacerbations and mortality (13). Epidemiological data for fibrinogen are currently being reviewed by the United States Food and Drug Administration for possible qualification as a biomarker to risk stratify COPD patients for mortality and exacerbation risk (14). Similar to fibrinogen, plasma C-reactive protein and serum inflammatory cytokines, such as interleukin-6, are found in higher levels during COPD exacerbations and can be used to denote severity of disease $(15,16)$. However, the data for these biomarkers are less compelling than those for fibrinogen.
While these inflammatory biomarkers can detect severe COPD with relative sensitivity, they lack overall specificity for lung disease (15). On the other hand, proteins derived directly from lung tissue may better reflect the respiratory environment. The recent search for such proteins has brought to light surfactant protein D (SP-D), a product of type II pneumocytes. SP-D is a glycoprotein responsible for regulating innate immunity in the lung. It translocates to the systemic circulation in situations of increased lung permeability (such as in COPD), thus allowing for serum measurements. A large cross-sectional trial involving 1888 individuals with COPD demonstrated that not only were serum SP-D levels significantly higher than in non-COPD controls, but that levels in the highest ranges could predict the risk of exacerbations $(15,17)$. Moreover, treatment with prednisolone or inhaled corticosteroids resulted in significant decreases in SP-D levels by four weeks (18). Serum SP-D levels have also been found to relate to per cent emphysema on thoracic computed tomography scans and have been associated with more rapid progression of emphysema on computed tomography assessment over three years (19). Club cell secretory protein, a $16 \mathrm{kD}$ protein synthesized predominantly by club cells in distal airways, is another promising plasma pneumokine that is associated with accelerated decline in lung function and disease severity in COPD $(20,21)$. Future work could validate the normalization of SP-D and club cell secretory protein levels as goals of therapy and, thus, a role for these biomarkers in the management of COPD patients.

\section{THE FUTURE OF BIOMARKERS}

While numerous studies have illustrated the utility of exhaled NO, sputum cell counts and inflammatory blood markers in airways diseases, these biomarkers have yet to expand beyond the research realm into mainstream clinical medicine. To achieve clinical relevance, biomarkers must overcome several challenges, including the vast heterogeneity of disease phenotypes and the still poorly understood complex etiological pathways that lead to respiratory disease. One strategy involves combining available biomarkers into composite scores to increase sensitivity and specificity. An alternative strategy involves the promotion of burgeoning fields such as proteomics and genomics. Newly discovered proteins and genetic markers from such investigations could well serve the role of biomarkers in years to come. Despite the difficulties, continued investigation into biomarkers may yet yield tools that can revolutionize clinical decision making, aid the development and implementation of therapies, and improve our recognition of airway diseases.

DISCLOSURES: JML has no disclosures. DDS is a Canada Research Chair in COPD. DDS has received honoraria for speaking engagements from AstraZeneca, GlaxoSmithKline, Merck, Takeda, and Grifols over the previous three years and has sat on advisory committees for AstraZeneca, Novartis, Merck, Takeda and Grifols over the previous three years.

\section{REFERENCES}

1. Jones PW. Health status and the spiral of decline. COPD 2009;6:59-63.

2. Yoon HI, Sin DD. Biomarkers of therapeutic response in patients with chronic obstructive pulmonary disease: A critical review of the literature. Drugs 2011;71:1821-37.

3. Alving K, Weitzberg E, Lundberg JM. Increased amount of nitric oxide in exhaled air of asthmatics. Eur Respir J 1993;6:1368-70.

4. Smith AD, Cowan JO, Brassett KP, et al. Exhaled nitric oxide: A predictor of steroid response. Am J Respir Crit Care Med 2005;172:453-9.

5. Dweik RA, Sorkness RL, Wenzel S, et al. Use of exhaled nitric oxide measurement to identify a reactive, at-risk phenotype among patients with asthma. Am J Respir Crit Care Med 2010;181:1033-41.

6. Smith AD, Cowan JO, Brassett KP, Herbison GP, Taylor DR. Use of exhaled nitric oxide measurements to guide treatment in chronic asthma. N Engl J Med 2005;352:2163-73.

7. Szefler SJ, Mitchell H, Sorkness CA, et al. Management of asthma based on exhaled nitric oxide in addition to guideline-based treatment for inner-city adolescents and young adults: A randomised controlled trial. Lancet 2008;372:1065-72. 
8. Petsky HL, Cates CJ, Li A, Kynaston JA, Turner C, Chang AB. Tailored interventions based on exhaled nitric oxide versus clinical symptoms for asthma in children and adults. Cochrane Database Syst Rev 2009:CD006340.

9. Smith AD, Cowan JO, Filsell S, et al. Diagnosing asthma: Comparisons between exhaled nitric oxide measurements and conventional tests. Am J Respir Crit Care Med 2004;169:473-8.

10. Green RH, Brightling CE, McKenna S, et al. Asthma exacerbations and sputum eosinophil counts: A randomised controlled trial. Lancet 2002;360:1715-21.

11. Jayaram L, Pizzichini MM, Cook RJ, et al. Determining asthma treatment by monitoring sputum cell counts: Effect on exacerbations. Eur Respir J 2006;27:483-94.

12. Petsky HL, Kynaston JA, Turner C, et al. Tailored interventions based on sputum eosinophils versus clinical symptoms for asthma in children and adults. Cochrane Database Syst Rev 2007:CD005603.

13. Duvoix A, Dickens J, Haq I, et al. Blood fibrinogen as a biomarker of chronic obstructive pulmonary disease. Thorax 2012, June 28 (Epub ahead of print).

14. Rosenberg SR, Kalhan R. Biomarkers in chronic obstructive pulmonary disease. Transl Res 2012;159:228-37.

15. Wedzicha JA, Seemungal TA, MacCallum PK, et al. Acute exacerbations of chronic obstructive pulmonary disease are accompanied by elevations of plasma fibrinogen and serum IL-6 levels. Thromb Haemost 2000;84:210-5.

16. Man SF, Connett JE, Anthonisen NR, Wise RA, Tashkin DP, Sin DD. C-reactive protein and mortality in mild to moderate chronic obstructive pulmonary disease. Thorax 2006;61:849-53.

17. Lomas DA, Silverman EK, Edwards LD, et al. Serum surfactant protein $\mathrm{D}$ is steroid sensitive and associated with exacerbations of COPD. Eur Respir J 2009;34:95-102.

18. Sin DD, Man SF, Marciniuk DD, et al. The effects of fluticasone with or without salmeterol on systemic biomarkers of inflammation in chronic obstructive pulmonary disease. Am J Respir Crit Care Med 2008;177:1207-14.

19. Coxson HO, Dirksen A, Edwards LD, et al. The presence and progression of emphysema in COPD as determined by CT scanning and biomarker expression: A prospective analysis from the ECLIPSE study. Lancet Respir Med 2013 February 1 (Epub ahead of print).

20. Lomas DA, Silverman EK, Edwards LD, Miller BE, Coxson HO, Tal-Singer R. Evaluation of serum CC-16 as a biomarker for COPD in the ECLIPSE cohort. Thorax 2008;63:1058-63.

21. Vestbo J, Edwards LD, Scanlon PD, et al. Changes in forced expiratory volume in 1 second over time in COPD. N Engl J Med 2011;365:1184-92. 


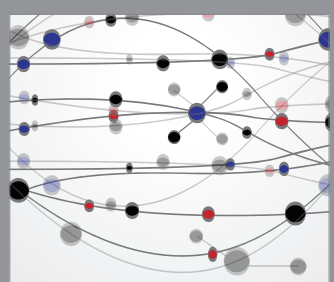

The Scientific World Journal
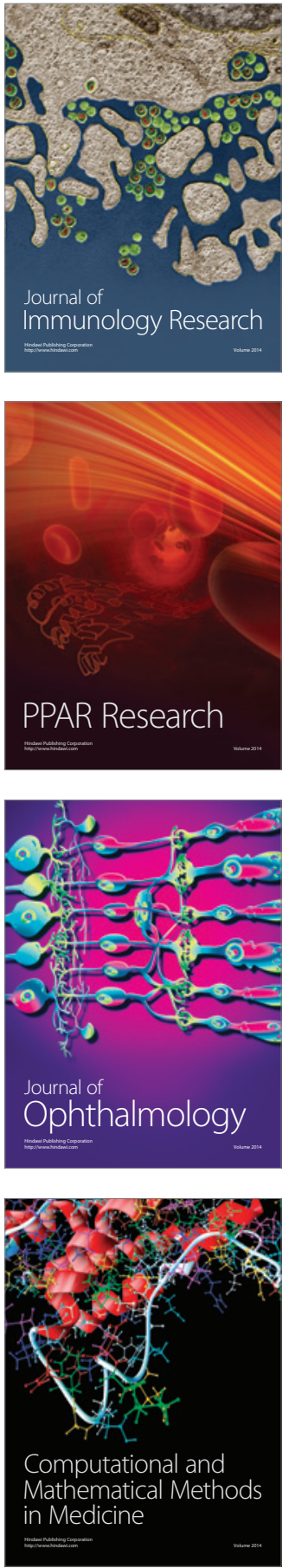

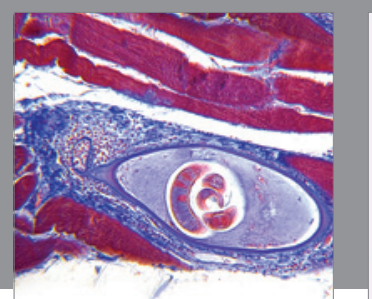

Gastroenterology Research and Practice

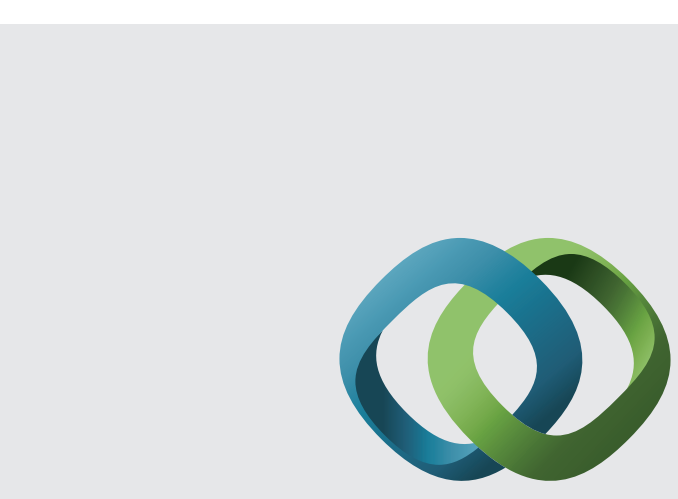

\section{Hindawi}

Submit your manuscripts at

http://www.hindawi.com
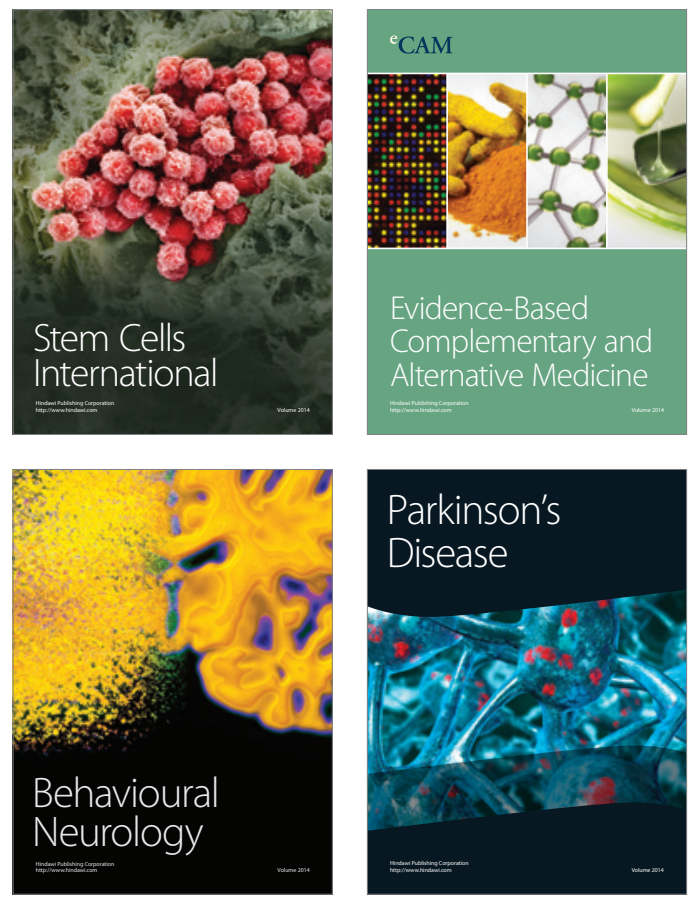
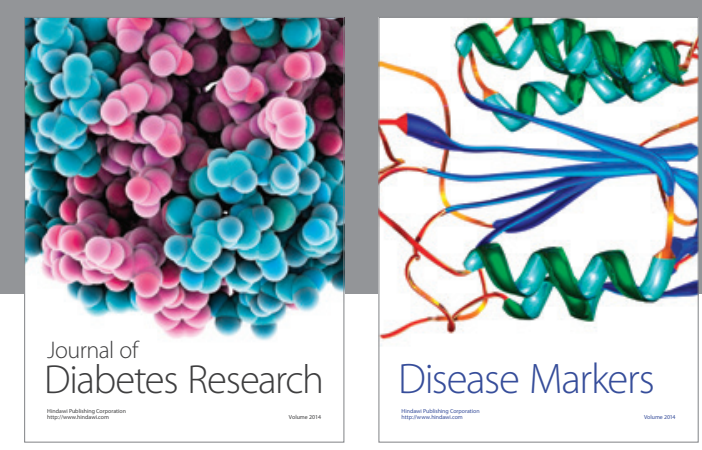

Disease Markers
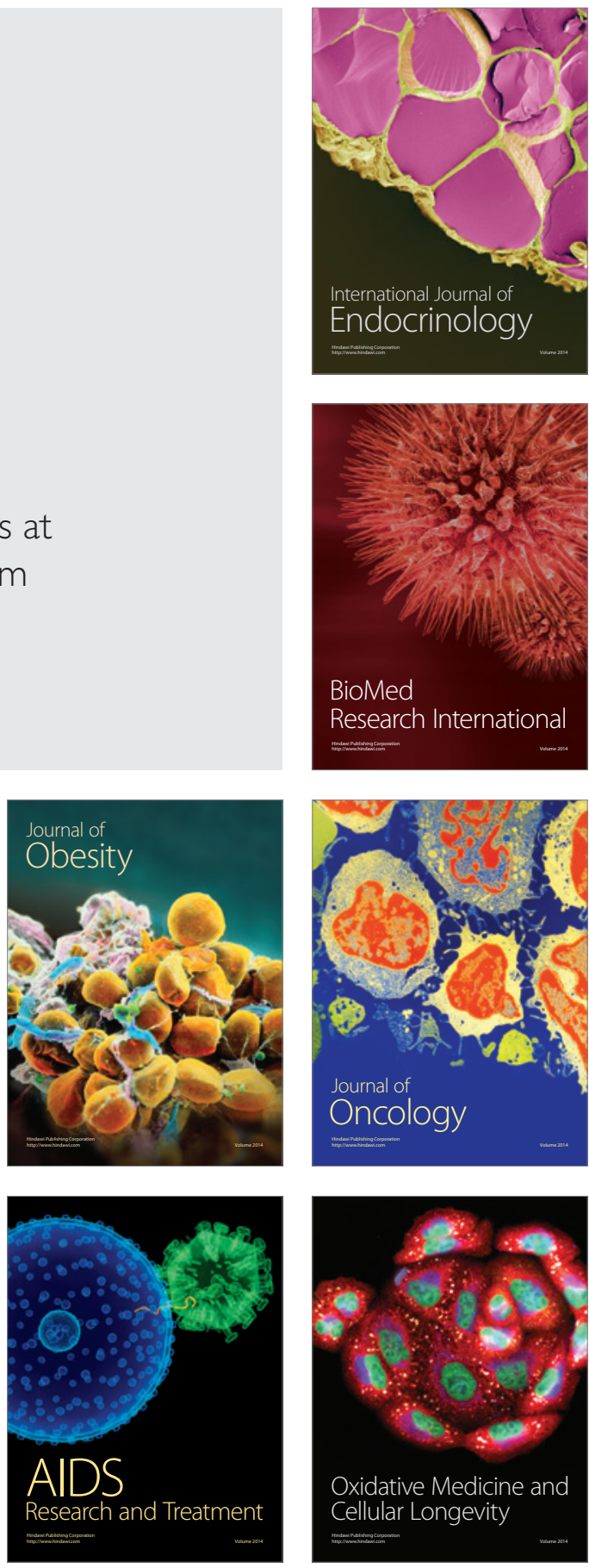